\title{
Research progress on modification of activated carbon
}

\author{
Mengran Liu ${ }^{1}$, and Cong $\mathrm{Xiao}^{2 *}$ \\ ${ }^{1}$ Chengwu County Environmental Protection Bureau, He'ze, Shandong 274200, China \\ ${ }^{2}$ Limited by Share Ltd Metallurgical Design Institute of Shandong Province, Jinan, Shandong 250101, China
}

\begin{abstract}
The paper overall the way and principle of how to modify activated carbon at home and abroad. Besides, the characteristics was given on physical, chemical modification respectively. The physical modification generally changed internal and external structure of the activated carbon, while chemical modification changed both its structure and surface properties. The advantages, disadvantages and the mechanism of the modifiers mentioned above are discussed, and their application are also prospected.
\end{abstract}

\section{Introduction}

Activated carbon is an amorphous carbon made from a special process. It has highly developed pore structure, huge specific surface area, varied surface chemical characteristics and high surface activity $[1,2]$. It is reported that the annual consumption of activated carbon in the world is about $275000 \mathrm{t}$ [3], which is used as an adsorbent for the removal of pollutants in the environment [4]. In addition, activated carbon can be used as catalyst carrier [5], electrode material [6], and can also be used for separation, concentration and decolorization [7]. According to the extensive study of activated charcoal by scholars at home and abroad, it is determined by two factors that activated carbon has strong adsorption properties: the surface structure characteristics of activated carbon (including specific surface area, pore structure and pore volume, etc.) and surface chemical properties (including surface acidity and basicity, functional groups and electrochemical properties) [1, 811]. Therefore, physical and chemical modification of activated carbon, making it have specific functional groups and changing pore structure to obtain multiple varieties, functional and high quality special activated carbon is urgent need to prepare.

\section{Physical modification method}

The principle of physical adsorption of activated carbon is that the pore diameter of activated carbon is much larger than or greater than or equal to the characteristics of adsorbate molecules, so that the molecules of adsorption can enter the pores of activated carbon surface, and then adsorb and remove the adsorbents. The common activated carbon has some disadvantages, such as high ash content, wide micropore distribution, small specific surface area and poor adsorption property [12]. In order to make active carbon have special properties and uses, it is usually modified to increase the specific surface area and pore size distribution.

\subsection{Gas modification method}

Activated carbon is modified by physical method. First, carbonization of raw materials is carried out to remove volatile matter, and then carbide is modified by gas. Pore structure is formed through opening, reaming and creating new holes. The typical modified gas has water vapor, $\mathrm{CO}_{2}$ and so on. The main reactions occurred (1) $\sim(2)$.

$$
\begin{gathered}
\mathrm{C}+\mathrm{H}_{2} \mathrm{O} \rightarrow \mathrm{H}_{2}+\mathrm{CO} \\
\mathrm{C}+\mathrm{CO}_{2} \rightarrow 2 \mathrm{CO}
\end{gathered}
$$

Hakan Demira 1[13] was used to modify the active carbon of olive residue at $700 \sim 900^{\circ} \mathrm{C}$ with the flow rate of $0.08 \mathrm{~mL} / \mathrm{min}$. The results showed that the surface area increased from $523 \mathrm{~m}^{2} / \mathrm{g}$ to $1106 \mathrm{~m}^{2} / \mathrm{g}$ and the total pore volume increased from $0.2981 \mathrm{~cm}^{3} / \mathrm{g}$ to $0.6067 \mathrm{~cm}^{3} / \mathrm{g}$ after the modification of activated carbon from olive residue. $\mathrm{Su}[14]$ used the water vapor and $\mathrm{CO}_{2}$ modified $0.28 \sim 0.90$ $\mathrm{mm}$ coconut shell activated carbon. After the reaction of $10 \sim 17 \mathrm{~h}$, the activated carbon with a specific surface area of more than $2700 \mathrm{~m}^{2} / \mathrm{g}$ was prepared.

\subsection{Microwave modification method}

The principle of microwave heating is to make use of the irregular movement of molecules inside the body to generate heat by friction, so as to rapidly and effectively heat the object, so that the surface functional groups of the activated carbon will react with the modifier adequately. The physical structure of activated carbon is adjusted by changing the microwave power and frequency, the time of radiation and the carrier gas. At the same time, the increase of the temperature of the system will further carbonization and change the pore structure [15]. Microwave heating has the advantages of high efficiency, low energy consumption, no pollution, energy saving and high efficiency, easy to control and so on. 
Jiang [16-18] investigated the effects of microwave power, activated carbon and carrier gas flow rate on the heating behavior of activated carbons in the microwave field, and the activated carbons with different particle sizes were modified. The analysis of finished products showed that the specific surface area of activated carbon changed little, the pore volume decreased slightly, the basic crystallites increased, the graphitization degree increased, the surface oxygen functional groups were decomposed in the form of $\mathrm{COx}$, and the nitrogen content in pyrrole nitrogen form increased. Cao [19] made the pore channel of activated carbon more smooth by microwave modification of activated carbon, but at the same time it leads to the narrow channel and the contraction of carbon skeleton. Menendez [20] used microwave treated activated carbons showed that most of the oxygenated functional groups on the surface of activated carbons were removed while $\mathrm{N}_{2}$ was protected, while $\mathrm{pH}$ values increased significantly.

\subsection{Heating method}

Using heating as a modification technology to modify activated carbon, changing the physical characteristics of activated carbon (specific surface area, pore volume and so on), improving its removal efficiency is also one of the research directions. Amina [21] treated the activated carbon at high temperature. After modification, the specific surface area of activated carbon increased $(+7.2 \%$, $400{ }^{\circ} \mathrm{C},+6.6 \%, 600{ }^{\circ} \mathrm{C}$ ), and the total pore volume increased $\left(+6.8 \%, 400{ }^{\circ} \mathrm{C},+8.6 \%, 600{ }^{\circ} \mathrm{C}\right)$, but had no significant effect on the surface chemical properties of activated carbon. Rangel-Mendez [22] study of steam or steam and methane mixed gas under high temperature $\left(1000{ }^{\circ} \mathrm{C}\right)$ modification of activated carbon, the results showed that the activated carbon microporous and mesoporous volume increased $50 \% \sim 70 \%, 65 \% \sim 90 \%$. The modified activated carbon can change the surface chemical properties of the activated carbon while changing the surface structure of the activated carbon. Heating treatment can destroy the unstable oxygen functional groups on the surface of activated carbon [21], and weaken the chelating ability of activated carbon and metal ions, thereby reducing the adsorption capacity of metal ions. However, high temperature is beneficial to the formation of alkaline groups on the surface of activated carbon, which is beneficial to the adsorption of organic matter in aqueous solution by activated carbon [8].

\section{Chemical modification method}

The chemical composition of activated carbon and the species and quantity of active functional groups on the surface have an important influence on the adsorption and catalysis. Therefore, it is of great significance to modify the activated carbon according to the different adsorbate. The main purpose of surface chemical modification is to change the surface acid and basicity of activated carbon, introduce or remove some surface functional groups, so that activated carbon has some special adsorption or catalytic properties.

\subsection{Oxidation modification method}

Oxidative modification is to adjust the appropriate temperature and react with the strong oxidants on the surface of activated carbon, so as to improve the content of oxygen-containing functional groups, such as carboxyl, phenolic hydroxyl, ester and carbonyl, and enhance the polarity and hydrophilicity of the surface [12]. The main oxidants commonly used are $\mathrm{HCl}, \mathrm{H}_{2} \mathrm{SO}_{4}, \mathrm{HNO}_{3}, \mathrm{HClO}_{3}$, $\mathrm{H}_{2} \mathrm{O}_{2}$ and so on [23-26]. The types and quantities of oxygen functional groups on the surface were changed by the reaction of different oxidants with activated carbon. The higher the degree of oxidation, the more the content of oxygen functional groups. Gil [27] used $\mathrm{HNO}_{3}$ and $\mathrm{H}_{2} \mathrm{O}_{2}$ to modify activated carbon, and the effect of temperature was discussed. The results showed that when $\mathrm{HNO}_{3}$ was used as oxidant, the surface properties of activated carbon were greatly affected by temperature. When the temperature was increased to $363 \mathrm{~K}$, the pore size increased gradually when the temperature was less than $333 \mathrm{~K}$. But when the $\mathrm{H}_{2} \mathrm{O}_{2}$ is modified, the effect of temperature is much smaller. Liu [28] modified the mesoporous activated carbon by $\mathrm{HNO}_{3}$, and then used it as a non-metallic catalyst to improve the conversion of propane. The results show that the oxygen containing functional groups on the surface of the modified activated carbon increase and can play an active role in the process of deoxidization.

\subsection{Reductive modification method}

The surface functional groups of activated carbon surface can be reduced and modified by reducing agents at proper temperature, which can improve the relative content of alkaline groups and enhance the non-polar surface, thereby improving the adsorption performance of activated carbon for non-polar substances. The methods of reducing modification are mainly concentrated on the high temperature treatment of activated carbon by inert gases such as $\mathrm{H}_{2}$ and $\mathrm{N}_{2}$. The surface reduction can also cause the change of the structure of the surface of the activated carbon.

Zhang [29] used $\mathrm{NaOH}$ to modify activated carbon. It was found that the surface oxygen containing functional groups decreased significantly, and the specific surface area and the concentration of pore volume increased with the increase of alkali concentration, which increased the adsorption capacity of methane. Gao [30] used $\mathrm{H}_{2}$ modified activated carbon materials, change the pore properties of activated carbon materials after no significant change, but because of the surface oxygen groups, especially oxygen acid groups were significantly decreased, the adsorption capacity of the activated carbon for phenol increased nearly 2.5 times. Gu [31] used ammonia and aniline to modify the activated carbon, which partially eliminated the negative surface groups and enhanced the adsorption capacity of Au (III). Because when using concentrated ammonia and other polar aniline solution, the surface of the activated carbon acid reactive groups with ammonia and aniline, and then removed by heating, increasing the pore radius, for larger $\mathrm{AuCl}^{4-}$ ions into the pore, also reduces the electrostatic negative 
electricity on the surface of the $\mathrm{AuCl}^{4-}$ ion repulsion, thus improving the adsorption capacity of the activated carbon. Alessandro [32] used a $\mathrm{NaOH}$ impregnation ratio of 3: 1 to the reduction of Australian nut shell based activated carbon. The results show that there are a large number of basic functional groups on the surface of activated carbon after reduction and modification, and the specific surface area of BET is $1524 \mathrm{~m}^{2} / \mathrm{g}$. After $50 \mathrm{~h}$ reaction, the conversion rate of propane was increased from $22.4 \%$ to $86.6 \%$.

\subsection{Acid-base modified method}

\subsubsection{Acid modification}

The acid modification technology of activated carbon is a typical wet oxidation technology. It means that using $\mathrm{HNO}_{3}, \mathrm{H}_{2} \mathrm{O}_{2}, \mathrm{HClO}, \mathrm{H}_{2} \mathrm{SO}_{4}, \mathrm{CH}_{3} \mathrm{COOH}$, citric acid and other oxidants on the activated carbon oxidation process under appropriate conditions, by changing the number and type of activated carbon surface oxygen functional groups, to improve the ability of removal of metal ions in aqueous solution. Meenakshi [33] studied the mechanism of $\mathrm{Cu}^{2+}$ adsorption on activated carbon. It was found that the unsaturated $\mathrm{C}=\mathrm{C}$ on the surface of activated carbon was attacked by oxygen atom to form acidic structures such as carboxyl and lactone groups. In the aqueous solution, acid functional groups hydrolyze $\mathrm{H}^{+}$, making the surface of the activated carbon with a negative contact site, which is combined with the positive metal ions in the solution. Badie [34] studied the method of pyrolysis modified by $\mathrm{H}_{3} \mathrm{PO}_{4}$ and the result showed that it can promote the formation of oxygen-containing functional groups on the surface of activated carbon, and the adsorption capacity for $\mathrm{Pb}^{2+}$ can reach $299 \mathrm{mg} / \mathrm{g}$ (about two times before modification).

\subsubsection{Alkali modification}

The alkali modification of activated carbon means using $\mathrm{NaOH}$, ammonia (gaseous / liquid) and other basic reagents to modify activated carbon to improve the ability of reducing carbon and the adsorption capacity of organic and acidic gases [34-36]. Przepiórski [37] study showed that the adsorption capacity of activated carbon to phenol in aqueous solution increased by $29 \%$ after the modification of high temperature $\left(400 \sim 800{ }^{\circ} \mathrm{C}\right)$ in the gaseous ammonia environment. Mohammad[38] modified the activated carbon by oxidation pretreatment and high temperature $\left(800{ }^{\circ} \mathrm{C}\right)$ ammonia modification. After modification, the microporous structure of activated carbon is increased, the surface acidic oxygen functional groups are reduced, the surface alkaline of activated carbon is enhanced, and the adsorption capacity of $\mathrm{CO}_{2}$ is increased. Valerie [39] used high temperature $\left(700{ }^{\circ} \mathrm{C}\right)$ and $\mathrm{NH}_{3}$ modified method to treat activated carbon powder to improve its redox characteristics in microbial fuel cell. The results show that the redox ability of the modified activated carbon powder is enhanced under the neutral condition. The amount of oxygen functional groups on the surface decreased by $29 \%$ to $58 \%$, the nitrogen content increased by $1.8 \%$, and the surface alkalinity increased.

\section{Load metal modification method}

The surface load is modified by loading the metal ions in some soluble salt solutions to the surface of the activated carbon. Oxidizing redox reaction with the surrounding carbon atoms at high temperatures and it causes the loss of the surrounding carbon atoms to reach the purpose of enlarging the pores or metal ions themselves have a good ability to adsorb a particular substance. Qiao [40] were tested with $\mathrm{Fe}\left(\mathrm{NO}_{3}\right)_{3}$ and $\mathrm{Fe}_{2}\left(\mathrm{SO}_{4}\right)_{3}$ for activated carbon. The results show that at high temperature, the reaction of NOx and SOx to the pore channel of activated carbon is released by the decomposition of metal salt, and the pore size is increased. At the same time, the metal oxide metal oxide is reduced by activated carbon at high temperature, and the pore size is enlarged. In the presence of metal, the activation of the pore wall of activated carbon increases the mesoporous rate of activated carbon. Yang [41] used $\mathrm{FeCl}_{3}$ as chemical additive and $\mathrm{CO}_{2}$ as activator. The activated carbon was modified by chemical physical mixed activation method. The experimental results show that the pore structure and pore size distribution of activated carbon can be greatly improved by $\mathrm{FeCl}_{3}-\mathrm{CO}_{2}$ system. After modification, the average pore size of activated carbon decreased slightly, but the specific surface area and total pore volume increased by one times more than that of the raw carbon, and the pore size distribution was more uniform. Yu [42] loads $\mathrm{Ag}^{+}, \mathrm{Ni}^{2+}$, $\mathrm{Cu}^{2+}, \mathrm{Zn}^{2+}$ and $\mathrm{Fe}^{2+}$ plasma on activated carbon. It is proved that the adsorption capacity of benzo thiophene containing sulfur organic compounds in oil can be obtained by loading different metal ions.

\section{Conclusion}

This study summarizes the modification methods of activated carbon and the characteristics of the modified methods. Acid modification is the most studied and most mature method of modification so far. Heating modification and alkali modification are beneficial to improve the adsorption of activated carbon to organic matter. When the load is modified, the chemical material can be loaded on the surface of the activated carbon to enhance its adsorption capacity to the target material. The special properties of activated carbon have been widely used in environmental treatment as an adsorbent. With the development of activated carbon modification technology, activated carbon can be specially modified according to the characteristics of pollutants in the environment, so as to realize the specialization of activated carbon in environmental treatment.

\section{Reference}

1. P. Chingombe, B.Saha, R.J. Wakeman. CARBON 43, 3132-3143 (2005) 
2. T.M. Alslaibi, I. Abustan, M.A. Ahmad, Eur. J CHEM TECHNOL BIOT 88, 1183-1190 (2013)

3. B. Agarwal, P.K. Thakur, C. Balomajumder. CHEM ENG COMMUN 200, 1278-1292 (2013)

4. O. Ioannidou, A. Zabaniotou. RENEW SUST ENERG REV 11, 1966-2005 (2007)

5. M. Kubota, A. Hata , H. Matsuda. CARBON 47, 2805-2811 (2009)

6. Y. Liu, Z.Hu, K.Xu, Eur. ACTA PHYS-CHIM SIN 24, 1143-1148 (2008)

7. M.F.R. Pereira, S.F. Soares, J.J.M. Órfão, Eur. CARBON 4, 811-821 (2003)

8. C.Y. Yin, M.K. Aroua, M.A.W.D. Wan.SEP PURIF TECHNOL52, 403-415 (2007)

9. Y. Han. TECHNIGUES AND EQUIPMENT FOR ENVIRO.POLL.CONT, (2003)

10. P.Wang, H.L. Zhang. CARBON TEC, (2003)

11. X.Y. Chen, X.L Lin, Q.H. Wei, Eur.SCI TECHN ENG, (2008)

12. X. Liang, X. Wang. TECHN WATER TREAT 37, 1-6 (2011)

13. H. Demiral, D. Llknur. CHEM ENG RES DES 89 , 206-213 (2011)

14. W. Su, L. Zhou, Y.P. Zhou. Chem. Ind. Forest Prod 26, 49-52 (2006)

15. L. Zhang, H.U. Jiapeng, S. Zhao, Eur. MATER REV, (2009)

16. W.J. Jiang, X. Jiang, X.F. Zhu, Eur. Chem. Ind. Forest Prod, 24, 21-24, (2004)

17. W. Jiang, J. Xia, X. Zhu, Eur. Chem. Ind. Forest Prod, 24, 39-42, (2003)

18. B. Yang, W. Jiang, Q. Chang. J LANZHOU JIAOTONG UNIV, 86, 46-50, (2006)

19. X.Q. Cao, X.M. Huang, S.R. Liu, Eur. J XIAN UNIV ARCH TECHNO, (2008)

20. J.A. Menéndez, E.M. Menéndez, M.J. Iglesias, Eur. CARBON 37, 1115-1121 (1999)

21. A.A. Attia, W.E. Rashwan, S.A. Khedr. DYES PIGMENTS 69, 128-136 (2006)

22. J.R. Rangel-Mendez, F.S. Cannon. CARBON 43,
467-479 (2005)

23. P. Vinke, M.V.D. Eijk, M.Verbree, Eur. CARBON 32, 675-686 (1994)

24. N.Wibowo, L. Setyadhi, D. Wibowo, Eur. J HAZARD MATER 146, 237 (2007)

25. W. Huang, S.K. Sun, L.I. Yu-Jie, Eur. BIOMASS CHEM ENG, (2006)

26. J.L. Figueiredo, M.F.R. Pereira, M.M.A. Freitas, Eur. CARBON 37, 1379-1389 (1999)

27. A. Gil, G.D.L. Puente, P. Grange. MICROPOR MESOPOR MAT 12, 51-61 (1997)

28. L. Liu, Q.F. Deng, Y.P. Liu, Eur. CHEM COMMUN 16, 81-85 (2011)

29. M.Z. Zhang, L. Li, J.X. Liu, Eur. J ENVIRON SCICHINA 34, 39 (2013)

30. F.Gao, J.W. Patrick, A. Walker. COMPOS SCI TECHNOL 57, 483-490 (1997)

31. J. Gu, D. Hu, W. Wang, Eur. BIOSENS BIOELECTRON 68, 27-33 (2015)

32. A.C. Martins, O. Pezoti, A.L. Cazetta, Eur. CHEM ENG J 260, 291-299 (2015)

33. M. Goyal, V.K. Rattan, D. Aggarwal, Eur. COLLOID SURFACE A 190, 229-238 (2001)

34. B.S. Girgis, A.A. Attia, N.A. Fathy. COLLOID SURFACE A 299, 79-87 (2007)

35. N.M. Haimour, S. Emeish. WASTE MANAGE 26, 651-660 (2006)

36. 36. L. Monser, N. Adhoum. SEP PURIF TECHNOL 26, 137-146 (2002)

37. J. Przepiórski. J HAZARD MATER 135, 453-456 (2006)

38. M.S. Shafeeyan, M.A.W.D. Wan, A. Houshmand, Eur. APPL SURF SCI 257, 3936-3942 (2011)

39. V.J. Watson, C.N. Delgado, B.E. Logan. J POWER SOURCES 242, 756-761 (2013)

40. W.M. Qiao, Y. Song, S.H. Yoon, Eur. NEW CARBON MATER 20,198-204 (2005)

41. J.P. Yang, Y.H. Tian. J POWER SOURCES, (2005)

42. Y.U. Mo-Xin. J Appl Biomater Function Mater 37, 1816-1818 (2006) 